\title{
openheart The importance of a balanced $\omega-6$ to $\omega-3$ ratio in the prevention and management of obesity
}

\author{
Artemis P Simopoulos, ${ }^{1}$ James J DiNicolantonio ${ }^{2}$
}

To cite: Simopoulos AP, DiNicolantonio JJ. The importance of a balanced $\omega-6$ to $\omega-3$ ratio in the prevention and management of obesity. Open Heart 2016;3:e000385 doi:10.1136/openhrt-2015000385

Accepted 8 January 2016

\section{CrossMark}

\section{${ }^{1}$ The Center for Genetics, Nutrition and Health, Washington, DC, USA 2Saint Luke's Mid America Heart Institute, Kansas, Missouri, USA}

\section{Correspondence to} Artemis P Simopoulos; cgnh@verizon.net and James J DiNicolantonio; jjdinicol@gmail.com
In 1980, a significant segment of the US population was already overweight or obese, but obesity standards did not exist. Therefore, the National Institutes of Health (NIH) held the Workshop on Body Weight, Health and Longevity to correct the deficiency so that data could be improved. The workshop concluded:

In the United States, the weight associated with the greatest longevity tends to be below the average weight of the population under consideration, if such weights are not associated with a history of significant medical impairment. Overweight persons tend to die sooner than average-weight persons, especially those who are overweight at younger ages. The effect of being overweight on mortality is delayed and may not be seen in short-term studies. Cigarette smoking is a potential confounder of the relationship between obesity and mortality. Studies on body weight, morbidity, and mortality must be interpreted with careful attention to the definitions of obesity or relative weight used, preexisting morbid conditions, the length of follow-up, and confounders in the analysis. The terminology of body weight standards should be defined more precisely and cited appropriately. An appropriate database relating body weight by sex, age, and possibly frame size to morbidity and mortality should be developed to permit the preparation of reference tables for defining the desirable range of body weight based on morbidity and mortality statistics. ${ }^{1}$

Based on body mass index (BMI), 1.5 billion people are overweight $\left(\mathrm{BMI} \geq 25.0 \mathrm{~kg} / \mathrm{m}^{2}\right)$ and 500 million of them are classified as obese $\left(\mathrm{BMI} \geq 30 \mathrm{~kg} / \mathrm{m}^{2}\right) .^{2-3}$ Since 1980 there have been many studies on the causes and management of obesity including behavioural studies, physical activity studies, nutritional studies ranging from high-protein low-carbohydrate low-fat, high-carbohydrate low-calorie diets and drugs for the treatment of obesity, yet despite all these efforts the US population continues to increase its weight and similar situations exist in other countries, both developed and developing. In developing countries, obesity coexists with undernourished and malnourished individuals. So far, no country has been able to either prevent overweight and obesity or maintain weight loss of its population.

International organisations and many scientists continue to consider obesity the result of an imbalance between energy intake and expenditure. Citing the law of thermodynamics, scientists and industries articulated the concept of 'a calorie is a calorie', which led to the development of a huge weight loss industry, various diets substituting 'calories for other calories' and books promoting 'eat less and exercise more'. These approaches continue to be espoused today, despite the scientific evidence that 'a calorie is not a calorie', and that the sources of calories are important in influencing human metabolism and appetite control. ${ }^{4-6}$ For example, calories from vegetable oils high in linoleic acid (LA), an $\omega-6$ fatty acid, are proinflammatory and thrombogenic, whereas calories from eating fish high in $\omega-3$ fatty acids are antiinflammatory and antithrombotic. High $\omega-6$ fatty acid intake increases white adipose tissue that is stored and prevents its browning. ${ }^{7} 8$ Furthermore, calories from $\omega-6$ fatty acid intake from vegetable oils high in LA (corn oil, sunflower, safflower, cottonseed, soya bean oil) have different effects on fat tissue development and type than calories from $\omega-3$ fatty acid intake high in $\alpha$-linolenic acid (ALA) (such as flaxseed oil, canola oil, perilla oil, chia oil). In addition, high $\omega-6$ fatty acid intake leads to an inflammatory state, which is at the basis of obesity and other chronic diseases, whereas calories from $\omega-3$ fatty acids have the opposite effect $^{9}{ }^{10}$ (box 1 and table 1$)$. $\omega-6$ and $\omega-3$ fatty acids are essential for health and must be obtained from the diet by all mammals including human beings. 
Box 1 Effects of ingestion of eicosapentaenoic acid (EPA) and docosahexaenoic acid (DHA) from fish or fish oil ${ }^{9}$

Decreased production of prostaglandin $\mathrm{E}_{2}\left(\mathrm{PGE}_{2}\right)$ metabolites

A decrease in thromboxane $A_{2}$, a potent platelet aggregator and vasoconstrictor

A decrease in leukotriene $B_{4}$ formation, an inducer of inflammation, and a powerful inducer of leucocyte chemotaxis and adherence

An increase in thromboxane $A_{3}$, a week platelet aggregator and weak vasoconstrictor

An increase in prostacyclin $\mathrm{PGI}_{3}$, leading to an overall increase in total prostacyclin by increasing $\mathrm{PGI}_{3}$ without a decrease in $\mathrm{PGI}_{2}$; $\mathrm{PGI}_{2}$ and $\mathrm{PGl}_{3}$ are active vasodilators and inhibitors of platelet aggregator

An increase in leukotriene $B_{5}$, a weak inducer of inflammation and a weak chemotactic agent

Table 1 Opposing effects of $\omega-6$ and $\omega-3$ fatty acids on obesity

\begin{tabular}{|c|c|c|}
\hline & $\omega-6$ & $\omega-3$ \\
\hline Adipose cells (tissue) & $\uparrow$ & $\downarrow$ \\
\hline White adipose tissues & $\uparrow$ & $\downarrow$ \\
\hline Brown adipose tissues & $\downarrow$ & $\uparrow$ \\
\hline Inflammation & $\uparrow$ & $\downarrow$ \\
\hline Triglycerides & $\uparrow$ & $\downarrow$ \\
\hline Muscle glycogen synthesis & & $\uparrow$ \\
\hline $\begin{array}{l}\text { Endogenous antioxidants (ie, superoxide } \\
\text { dismutase catalase) }\end{array}$ & $\downarrow$ & $\uparrow$ \\
\hline Oxidation & $\uparrow$ & $\downarrow$ \\
\hline Endocannabinoid tone & $\uparrow$ & $\downarrow$ \\
\hline Protein synthesis & & $\uparrow$ \\
\hline Mitochondrial biogenesis & & $\uparrow$ \\
\hline AMPK & & $\uparrow$ \\
\hline Akt & & $\uparrow$ \\
\hline Telomeres & $\downarrow$ & $\uparrow$ \\
\hline$N F-\kappa B$ & $\uparrow$ & $\downarrow$ \\
\hline $\operatorname{PPAR} \alpha$ & $\downarrow$ & $\uparrow$ \\
\hline Leptin resistance & $\uparrow$ & $\downarrow$ \\
\hline Insulin resistance & $\uparrow$ & $\downarrow$ \\
\hline Adiponectin & & $\uparrow$ \\
\hline Waist circumference & $\uparrow$ & $\downarrow$ \\
\hline
\end{tabular}

We now know that major changes have taken place in the food supply over the last 100 years, when food technology and modern agriculture led to enormous production of vegetable oils high in $\omega-6$ fatty acids, and changed animal feeds from grass to grains, thus increasing the amount of $\omega-6$ fatty acids at the level of LA (from oils) and arachidonic acid (AA) (from meat, eggs, dairy). This led to very high amounts of $\omega-6$ fatty acids in the food supply for the first time in the history of human beings. ${ }^{11-13}$ Traditionally, animals grazed. Grass contains ALA ( $\omega-3)$, whereas grains, corn and soya (which are now fed to animals) are high in LA ( $\omega-6)$. This imbalance in the amount of $\omega-6$ and $\omega-3$ fatty acids is a new phenomenon that was never a part of human evolution $^{11}$ (figure 1, table 2). Human beings evolved on a diet that had equal amounts of $\omega-6$ and $\omega-3$ fatty acids. This balanced ratio of $\omega-6$ to $\omega-3$ is critical to human development during pregnancy and lactation, in the prevention of chronic diseases and in their management. ${ }^{9} 1415$ The typical Western diet now provides an $\omega-6$ to $\omega-3$ ratio of around $16: 1$. High dietary intake of $\omega-6$ fatty acids as occurs today leads to increases in white adipose tissue and chronic inflammation, which are the "hallmarks of obesity'. ${ }^{8} \omega-6$ and $\omega-3$ fatty acids specifically metabolise to prostaglandins, thromboxane and leukotrienes. Prostaglandin $\mathrm{E}_{2}$ from AA leads to differentiation and proliferation of adipose tissue and prostaglandin $\mathrm{F}_{2 \alpha}$ also from AA prevents the browning of white adipose tissue, which is the good fat tissue as it increases thermogenesis, burning fat through the release of heat. $^{7816}$

The $\omega-6$ and $\omega-3$ fatty acids are metabolically and functionally distinct ${ }^{11}$ (box 1 and table 1 ). $\omega-3$ fatty acids decrease adipose tissue development and lead to weight loss. ${ }^{17-19}$ A recent study based on the NIH Women's Health Initiative clearly showed the importance of the $\omega-6$ to $\omega-3$ ratio in weight gain over a period of 10 years in healthy young women. ${ }^{20}$ High concentrations of $\omega-6$ in red blood cell membrane phospholipids were associated with increased risk of weight gain. ${ }^{20}$ Similarly, a high $\omega-6$ to $\omega-3$ ratio was also associated with increased risk of weight gain, whereas a high concentration of $\omega-3$ in red blood cell membrane phospholipids was associated with decreased risk. This is a very important study because the investigators used red blood cell membrane phospholipids instead of dietary intake based on food frequency questionnaires that are not as accurate. Dietary frequency questionnaires suffer from two very important deficiencies in carrying out studies on the

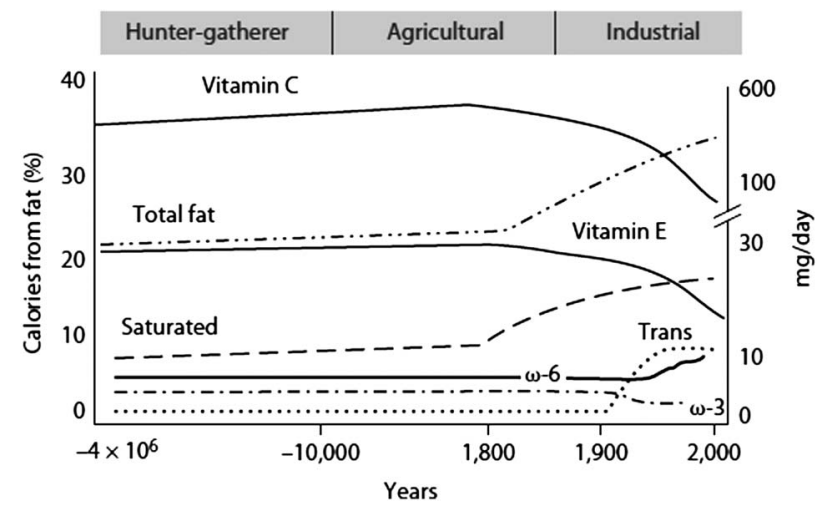

Figure 1 Hypothetical scheme of fat, fatty acid $(\omega 6, \omega 3$, trans and total) intake (as per cent of calories from fat) and intake of vitamins $E$ and $C$ (mg/day). Data were extrapolated from cross-sectional analyses of contemporary hunter-gatherer populations and from longitudinal observations and their putative changes during the preceding 100 years. 
Table $2 \omega 6$ to $\omega 3$ ratios in various populations

\begin{tabular}{lll}
\hline Population & $\omega 6: \omega 3$ & Reference \\
\hline Palaeolithic & $0.97^{\star}, \dagger$ & Eaton et $a \beta^{\beta 7}$ \\
Greece prior to 1960 & $1.00-2.00$ & Simopoulos ${ }^{14}$ \\
Current USA & 16.74 & Eaton et $a \beta^{\beta 7}$ \\
UK and Northern Europe & 15.00 & $\begin{array}{l}\text { Sanders }(2000)^{39} \\
\text { Japan }\end{array}$ \\
& 4.00 & $\begin{array}{l}\text { Sugano and } \\
\text { Hirahana } \\
(2000)^{40}\end{array}$ \\
& & $\begin{array}{l}\text { Pella et al }(2003)^{41} \\
\text { India rural }\end{array}$ \\
India urban & $5-6.1$ & Pella et al $(2003)^{41}$ \\
\hline
\end{tabular}

*Data from Eaton et al. ${ }^{37}$

†Assuming an energy intake of 35:35 of animal:plant sources.

relationship of essential fatty acids ( $\omega-6$ and $\omega-3)$. One is the well-known inaccuracy based on the memory of what people ate, and the other is the variation in the endogenous production of $\omega-6$ and $\omega-3$ fatty acids. What is actually being circulated in the blood and in red blood cell membrane phospholipids consists of dietary intake and the endogenous production of $\omega-6$ and $\omega-3$ fatty acids. These two factors account for the discrepancy in epidemiologic, observational and clinical intervention studies along with other factors listed in box 2, which must be taken into consideration while carrying out clinical intervention studies.

In the metabolism of the $\omega-6$ and $\omega-3$ fatty acids, there are genetic differences in the population that lead to variations in the amounts of AA $(\omega-6)$ and eicosapentaenoic acid (EPA) and docosahexaenoic acid (DHA) $(\omega-3)$ formed from LA and ALA, respectively (figure 2). In European populations, about one-third of the population has genetic variants-haplotype $\mathrm{D}$-that increase

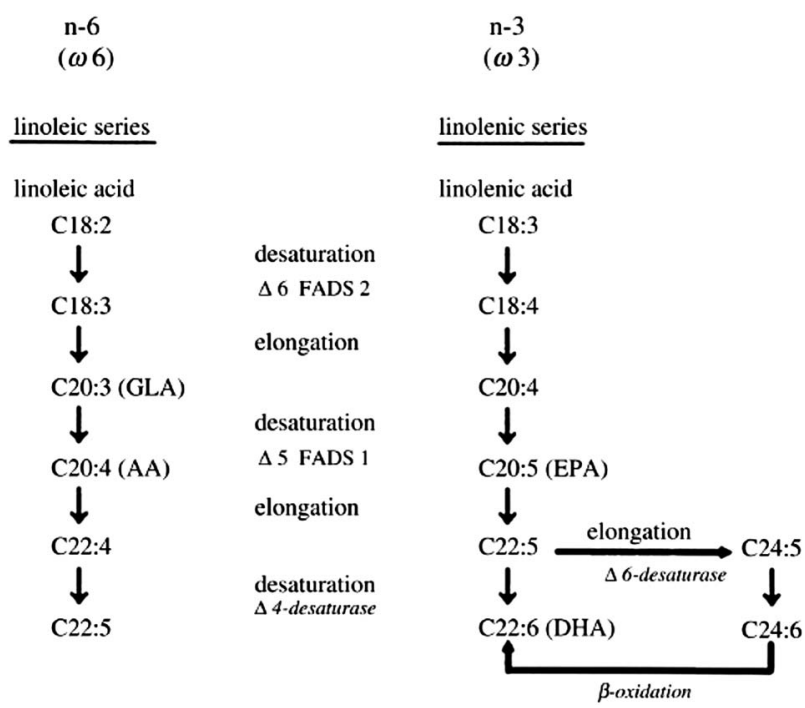

Figure 2 Desaturation and elongation of $\omega-3$ and $\omega-6$ fatty acids. The enzymes $\Delta 6$ desaturase and $\Delta 5$ desaturase are encoded by FADS2 and FADS1, respectively. AA, arachidonic acid; DHA, docosahexaenoic acid; EPA, eicosapentaenoic acid; FAD, fatty acid desaturase; GLA, $\gamma$-linoleic acid. the production of AA, from the high LA in the diet. This genetic variation could account for an additional increase of AA of about $25 \%$ that is endogenously produced. In Africans, practically $99 \%$ of the population carries haplotype $\mathrm{D}$, whereas in African-Americans the frequency is about $50 \%$ depending on the admixture of the population. ${ }^{21} 22$ It is obvious then that when carrying out studies, one must include dietary intake and endogenous production represented by measurements of red blood cell membrane phospholipids. A high intake of LA from vegetable oils leads to a disproportionate increase in AA in individuals with haplotype D (genetic variants in fatty acid desaturase (FADS) 1 and FADS2) (figure 2), which increases the risk of obesity and its consequences, type 2 diabetes, cardiovascular disease, metabolic syndrome and cancer. Adipose tissue has a requirement for AA for adipose cell differentiation but in amounts equivalent (balanced $\omega-6$ to $\omega-3$ ratio) not a ratio of $16: 1$ as it is in the US food supply today and other developed countries). ${ }^{23} \omega-3$ fatty acids (EPA and DHA) decrease adipose tissue and produce lipid mediators-resolvins, protectins and maresins, which are neuroprotective and lead to resolution of inflammation. ${ }^{24}$ Furthermore $\omega-3$ fatty acids lead to increased fatty acid oxidation and mitochondrial biogenesis. ${ }^{8}$

There have been many studies using rodents with various results on the effects of $\omega-6$ and $\omega-3$ fatty acids on the genesis and management of obesity, with conflicting results due to differences in animal models, dose of $\omega-3$ fatty acids, observation time, etc. In animals, as in humans, it is very difficult to accurately measure dietary

\section{Box 2 Factors that affect outcomes in obesity studies ${ }^{5}$}

- Lack to determine the composition of the background diet in terms of $\omega-6$ and $\omega-3$ fatty acids and inflammatory markers, that is, the USA, UK and Northern European countries have the highest amount of linoleic acid $(L A)+$ arachidonic acid $(\mathrm{AA})$ in their diets, which competes with $\omega-3$ polyunsaturated fatty acids (PUFAs); they also have the lowest amount of vegetable and fruit intake, which are needed for optimal absorption of $\omega$-3 PUFA from supplements

- Background inflammation

- Some studies are using fish and others $\omega-3$ supplements; studies show that a continuous daily intake of $\omega$-3 supplements leads to higher concentrations in the blood than eating fish two times per week

Variation in the dose of $\omega$-3 fatty acids

- Variation in the number of subjects

Variation in the severity of disease

- Variation in the pharmacologic treatment

- Genetic variants predisposing to obesity

- Dietary intake by means of questionnaires instead of actual measurements of $\omega-3$ PUFAs in the red blood cell membrane phospholipids or plasma is a major problem that leads to conflicting results

Length of intervention

Genetic variants in the metabolism of $\omega-6$ and $\omega-3$ fatty acids 
intake. The Fat-1 mouse model bypasses these differences because the $\omega-3$ desaturase controls the formation of $\omega-3$ fatty acids from $\omega-6$, and at all times the amounts remain the same which cannot be done easily and accurately with dietary studies. Using this model, it has been shown that there is a threefold increase in $\omega-3$ fatty acids and a threefold decrease in $\omega-6$ fatty acids, and these changes decrease adipose tissue inflammation and increase $5^{\prime}$ adenosine monophosphate-activated protein kinase (AMPK) activation, which is the gatekeeper of energy. $^{18}$

Fatty acids act directly on the central nervous system (CNS) and influence food intake, insulin sensitivity and leptin sensitivity. High-fat diets rich in $\omega-6$ fatty acids, as in current Western diets, increase the risk of leptin resistance, diabetes and obesity in humans and rodents. ${ }^{25-27}$

A diet high in the $\omega-6$ to $\omega-3$ ratio causes an increase in the endocannabinoid signalling and related mediators, which leads to an increased inflammatory state, energy homeostasis and mood. ${ }^{28}$ In animal experiments, a high $\omega-6$ fatty acid intake leads to decreased insulin sensitivity in muscle and promotes fat accumulation in adipose tissue. Nutritional approaches with dietary $\omega-3$ fatty acids reverse the dysregulation of this system, improve insulin sensitivity and control body fat. A high $\omega-6$ to $\omega-3$ ratio in current Western diets coupled with an increased synthesis of proinflammatory cytokine interleukin 6 (IL-6) from the adipose tissue of an already overweight and obese population propagates obesity by increasing or maintaining chronic inflammation.

It is therefore essential to return to a balanced dietary $\omega-6$ to $\omega-3$ ratio based on data from evolutionary studies,${ }^{11}$ the Fat- 1 mouse model ${ }^{18}$ and the results of the $\mathrm{NIH}$ Women's Health Initiative clinical study. ${ }^{20}$ By decreasing $\omega-6$ and increasing $\omega-3$ in the diet, the proadipogenic pathway can be inhibited. The preferred ratio of $\omega-6$ to $\omega-3$ for optimal health is $1: 2 / 1$, which is consistent with the evolutionary aspects of diet. ${ }^{29}$ The time has come to return the $\omega-3$ fatty acids in the food supply and decrease the $\omega-6$ fatty acids by changing the cooking oils (figure 3) and eating less meat and more fish. The composition of the food supply must also change to be consistent with the evolutionary aspects of diet and the genetics of the population. The scientific evidence to balance the $\omega-6$ to $\omega-3$ ratio is robust and necessary for normal growth and development, prevention and treatment of obesity and its comorbidities including diabetes, cardiovascular disease and cancer. This can be accomplished by studies focusing on the metabolism of nutrients, genes and their function. ${ }^{7} 8{ }^{30-34}$ Genome-wide
Figure 3 The fatty acid content of common fats and oils. The chart shows the percentage of saturated fatty acids, monounsaturated fatty acids, linoleic acid and $\alpha$-linolenic acid in 13 commonly used fats and oils. $^{38}$

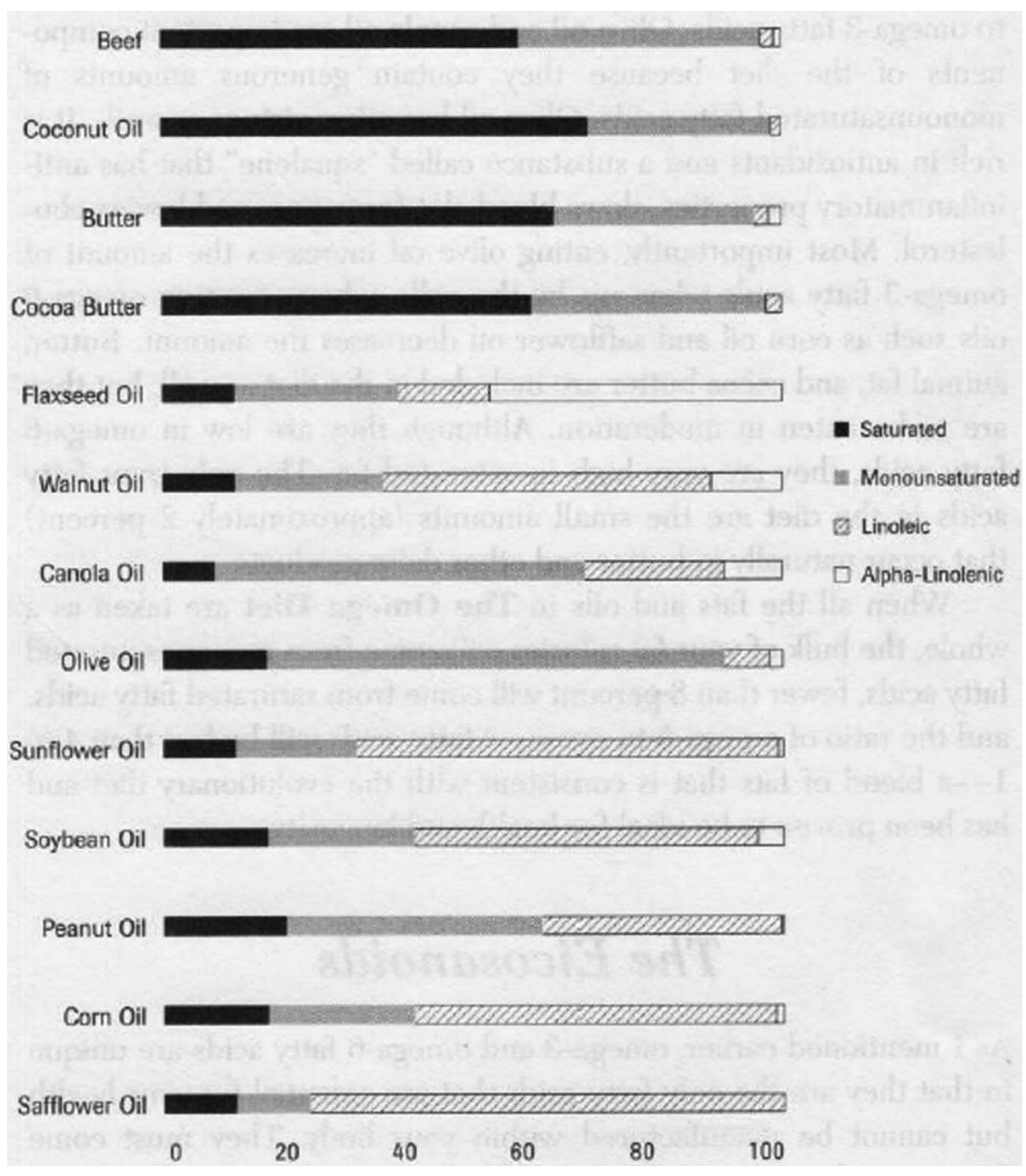


association studies (GWAS) have identified over 90 loci, and many single-nucleotide variants ( $\mathrm{SNVs}$ ) associated with BMI, with the majority of SNVs occurring in noncoding regions of the genome. Claussnitzer et $a l^{30}$ showed how to decipher non-coding regions and have presented a strategy to functionally analyse GWAS. Their study provided evidence that the risk allele rs $1411085 \mathrm{~T}$ to $\mathrm{C}$ SNV resulted in increased expression of IRX3 and IRX5 genes in preadipocytes, which shifted the development of these cells towards the 'White Program' and increased lipid storage, whereas genetic knockdown of IRX3 and IRX5 restored thermogenesis in adipocytes from persons at high risk of obesity. Thus, the risk allele functioned similarly to prostaglandin $\mathrm{E}_{2}$ and prostaglandin F2 $\alpha$ from $\omega-6$ fatty acids, whereas the genetic knockdown of IRX3 and IRX5 functioned similarly to $\omega-3$ fatty acid metabolites. AA metabolites prostacyclin and prostaglandin $\mathrm{E}_{2}$ increase white adipose tissue and decrease its browning. Human studies have shown a direct relationship between plasma AA levels and infant body weight, as well as between AA levels in adipose tissue lipids and BMI in children in Cyprus and Crete. ${ }^{35}{ }^{36}$ AA directly inhibits uncoupling protein-1 (UCP1) gene expression. Considering the high $\omega-6$ to $\omega-3$ fatty acid ratio of Western diets and the role of AA in adipose cell differentiation, proliferation and decreasing browning of white adipose tissue, further research should include studies on the effects of $\omega-3$ fatty acids in blocking the effects of the risk allele (rs 1411085). Clinical intervention studies must take into consideration the background diet, the genetics of the population and be free of confounding factors listed in box 2. It is the responsibility of the governments and international organisations to establish nutrition policies based on science and not continue along the same path of focusing exclusively on calories and energy expenditure, which have failed miserably over the past 30 years.

\section{Twitter Follow James J DiNicolantonio at @drjamesdinic}

Contributors APS conceived and outlined the paper, JJD provided additional input and references and both authors finalised the paper.

\section{Competing interests None declared.}

Provenance and peer review Not commissioned; externally peer reviewed.

Open Access This is an Open Access article distributed in accordance with the Creative Commons Attribution Non Commercial (CC BY-NC 4.0) license, which permits others to distribute, remix, adapt, build upon this work noncommercially, and license their derivative works on different terms, provided the original work is properly cited and the use is non-commercial. See: http:// creativecommons.org/licenses/by-nc/4.0/

\section{REFERENCES}

1. Simopoulos AP, Van Itallie TB. Body weight, health, and longevity. Ann Intern Med 1984;100:285-95.

2. Wang YC, McPherson K, Marsh T, et al. Health and economic burden of the projected obesity trends in the USA and the UK. Lancet 2011;378:815-25.

3. Adams KF, Schatzkin A, Harris TB, et al. Overweight, obesity, and mortality in a large prospective cohort of persons 50 to 71 years old. N Engl J Med 2006;355:763-78.
4. Simopoulos AP. Dietary omega-3 fatty acid deficiency and high fructose intake in the development of metabolic syndrome, brain metabolic abnormalities, and non-alcoholic fatty liver disease. Nutrients 2013;5:2901-23.

5. Simopoulos AP. The impact of the Bellagio report on healthy agriculture, healthy nutrition, healthy people: scientific and policy aspects and the international network of centers for genetics, nutrition and fitness for health. $J$ Nutrigenet Nutrigenomics 2015;7:191-211.

6. Page KA, Chan O, Arora J, et al. Effects of fructose vs. glucose on regional cerebral blood flow in brain regions involved with appetite and reward pathways. JAMA 2013;309:63-70.

7. Pisani DF, Ghandour RA, Beranger GE, et al. The $\omega 6$-fatty acid, arachidonic acid, regulates the conversion of white to brite adipocyte through a prostaglandin/calcium mediated pathway. Mol Metab 2014;3:834-47.

8. Pisani DF, Amri EZ, Ailhaud G. Disequilibrium of polyunsaturated fatty acids status and its dual effect in modulating adipose tissue development and functions. OCL 2015;22:D405.

9. Simopoulos AP. The importance of the omega-6/omega-3 Fatty Acid ratio in cardiovascular disease and other chronic diseases. Exp Biol Med (Maywood) 2008;233:674-88.

10. Patterson E, Wall R, Fitzgerald GF, et al. Health implications of high dietary omega- 6 polyunsaturated Fatty acids. J Nutr Metab 2012;2012:539426.

11. Simopoulos AP. Omega-3 fatty acids in health and disease and in growth and development. Am J Clin Nutr 1991;54:438-63.

12. Blasbalg TL, Hibbeln JR, Ramsden CE, et al. Changes in consumption of omega-3 and omega- 6 fatty acids in the United States during the 20th century. Am J Clin Nutr 2011;93:950-62.

13. Guyenet SJ, Carlson SE. Increase in adipose tissue linoleic acid of US adults in the last half century. Adv Nutr 2015;6:660-4.

14. Simopoulos AP. Essential fatty acids in health and chronic disease. Am J Clin Nutr 1999;70(Suppl 3):560S-9S.

15. Ailhaud G, Guesnet P. Fatty acid composition of fats is an early determinant of childhood obesity: a short review and an opinion. Obes Rev 2004;5:21-6.

16. Porter C, Chondronikola M, Sidossis LS. The therapeutic potential of brown adipocytes in humans. Front Endocrinol (Lausanne) 2015;6:156.

17. Martínez-Fernández L, Laiglesia LM, Huerta AE, et al. Omega-3 fatty acids and adipose tissue function in obesity and metabolic syndrome. Prostaglandins Other Lipid Mediat 2015;121(Pt A):24-41.

18. Li J, Li FR, Wei D, et al. Endogenous $\omega-3$ polyunsaturated fatty acid production confers resistance to obesity, dyslipidemia, and diabetes in mice. Mol Endocrinol 2014;28:1316-28.

19. Du S, Jin J, Fang W, et al. Does fish oil have an anti-obesity effect in overweight/obese adults? A Meta-Analysis of Randomized Controlled Trials. PLOS ONE 2015;10:e0142652.

20. Wang L, Manson JE, Rautiainen S, et al. A prospective study of erythrocyte polyunsaturated fatty acid, weight gain, and risk of becoming overweight or obese in middle-aged and older women. Eur J Nutr 2016;55:687-97.

21. Ameur A, Enroth S, Johansson A, et al. Genetic adaptation of fatty-acid metabolism: a human-specific haplotype increasing the biosynthesis of long-chain omega-3 and omega- 6 fatty acids. Am J Hum Genet 2012;90:809-20.

22. Dorajoo $\mathrm{R}$, Sun $\mathrm{Y}, \mathrm{Han} \mathrm{Y}$, et al. A genome-wide association study of $\mathrm{n}-3$ and $\mathrm{n}-6$ plasma fatty acids in a Singaporean Chinese population. Genes Nutr 2015;10:53.

23. Gaillard D, Négrel R, Lagarde M, et al. Requirement and role of arachidonic acid in the differentiation of pre-adipose cells. Biochem $J$ 1989;257:389-97.

24. Serhan CN, Chiang N, Van Dyke TE. Resolving inflammation: dual anti-inflammatory and pro-resolution lipid mediators. Nat Rev Immunol 2008 May;8:349-61.

25. Nuernberg K, Breier BH, Jayasinghe SN, et al. Metabolic responses to high-fat diets rich in n-3 or n-6 long-chain polyunsaturated fatty acids in mice selected for either high body weight or leanness explain different health outcomes. Nutr Metab (Lond) 2011;8:56.

26. Phillips CM, Goumidi L, Bertrais S, et al. Leptin receptor polymorphisms interact with polyunsaturated fatty acids to augment risk of insulin resistance and metabolic syndrome in adults. $J$ Nutr 2010;140:238-44.

27. Cheng L, Yu Y, Zhang Q, et al. Arachidonic acid impairs hypothalamic leptin signaling and hepatic energy homeostasis in mice. Mol Cell Endocrinol 2015;412:12-18.

28. Alvheim AR, Torstensen BE, Lin YH, et al. Dietary linoleic acid elevates the endocannabinoids 2-AG and anandamide and promotes weight gain in mice fed a low fat diet. Lipids 2014;49:59-69.

29. Simopoulos AP. Evolutionary aspects of diet and essential fatty acids. In: Hamazaki T, Okuyama H. eds. Fatty acids and lipids-new findings. World Rev Nutr Diet, 2001;88:18-27. 
30. Claussnitzer M, Dankel SN, Kim KH, et al. FTO Obesity Variant Circuitry and Adipocyte Browning in Humans. N Engl J Med 2015;373:895-907.

31. Rosen CJ, Ingelfinger JR. Unraveling the Function of FTO Variants. N Engl J Med 2015;373:964-5.

32. Mou Z, Hyde TM, Lipska BK, et al. Human obesity associated with an intronic SNP in the brain-derived neurotrophic factor locus. Cell Rep 2015;13:1073-80.

33. Laber S, Cox RD. Commentary: FTO obesity variant circuitry and adipocyte browning in humans. Front Genet 2015;6:318.

34. Golub N, Geba D, Mousa SA, et al. Greasing the wheels of managing overweight and obesity with omega-3 fatty acids. Med Hypotheses 2011;77:1114-20.

35. Savva SC, Chadjigeorgiou C, Hatzis C, et al. Association of adipose tissue arachidonic acid content with BMI and overweight status in children from Cyprus and Crete. Br J Nutr 2004;91:643-9.
36. Jensen CL, Prager TC, Fraley JK, et al. Effect of dietary linoleic/ alpha-linolenic acid ratio on growth and visual function of term infants. J Pediatr 1997;131:200-9.

37. Eaton SB, Eaton SBIII, Sinclair AJ, et al. Dietary intake of long-chain polyunsaturated fatty acids during the Paleolithic. World Rev Nutr Diet 1998;83:12-23.

38. Simopoulos AP, Robinson J. The omega diet. Harper Collins, 1999.

39. Sanders TA. Polyunsaturated fatty acids in the food chain in Europe. Am J Clin Nutr 2000;71:176S-8S.

40. Sugano M, Hirahara F. Polyunsaturated fatty acids in the food chain in Japan. Am J Clin Nutr 2000;71:189S-96S.

41. Pella D, Dubnov G, Singh RB, et al. Effects of an IndoMediterranean diet on the omega-6/ omega-3 ratio in patients at high risk of coronary artery disease: the Indian paradox. World Rev Nutr Diet. Basel, Karger 2003;92:74-80. 